Does the bilingual advantage extend to trilingualism?

Margrét D. Guðmundsdóttir

Valerie E. Lesk ${ }^{+}$

Division of Psychology

University of Bradford

Richmond Building

Bradford, West Yorkshire

BD7 1DP, UK

Tel: 00441274236775

${ }^{+}$Corresponding author 


\title{
Does the Bilingual Advantage extend to Trilingualism?
}

\begin{abstract}
This study examined whether the proposed bilingual advantage in inhibitory control and working memory can be extended to a trilingual advantage, and assessed any age-related effects on a continuum in young adults to older adults. Trilinguals, bilinguals and monolinguals' performance on the Simon task and a numerical version of the N-back task was compared. On the Simon task, there was no language group difference observed, although the data show an age-related decline in inhibitory control only in trilinguals, but not in bilinguals or monolinguals. No clear language group differences were observed between trilinguals and bilinguals on the N-back task, however an overall trilingual and bilingual disadvantage, compared to monolinguals, was observed. Together the results suggest that managing two or three languages, compared to just one, may have a negative impact on inhibitory control and working memory performance. Importantly, they highlight the need to control for a possible confounding effect of including trilinguals/multilinguals in bilingual cohorts and to ensure that participants in monolingual cohorts speak only one language.
\end{abstract}

Keywords: Ageing, bilingual advantage, inhibitory control, trilingualism, working memory 
Conflicts of Interest: The authors report no conflicts of interest. 


\section{Introduction}

Bilinguals superior ability to inhibit irrelevant information has been observed on non-linguistic interference tasks that typically involve conflict between an intended correct response and a irrelevant/misleading alternative, such as the Flanker task (Costa, Hernández, \& Sebastián-Gallés, 2008; Yang, Yang, \& Lust, 2011; Tao, Marzecová, Taft, Asanowicz, \& Wodniecka, 2011; Engel de Abreu, 2011; Kapa \& Colombo, 2013; Pelham \& Abrams, 2014), the Simon task (Schroeder \& Marian, 2012; Salvatierra \& Rosselli, 2010; Martin-Rhee \& Bialystok, 2008; Bialystok, Craik, \& Luk, 2004; Bialystok, Craik, \& Ryan, 2006) and the Stroop task (Blumenfeld \& Marian, 2014; Hernández, Costa, Fuentes, Vivas, \& Sebastián-Gallés, 2010; Bialystok \& dePape, 2009; Martin-Rhee \& Bialystok, 2008). According to Miyake and colleagues' theoretical framework (Miyake \& Friedman, 2012) inhibition and working memory may share underlying mechanisms, thus any effects of bilingualism might also extend to working memory. Research conducted on bilingualism and working memory performance further reported a bilingual advantage (Blom, Küntay, Messer, Verhagen, \& Leseman, 2014; Bialystok, Poarch, \& Luo, 2014; Luo, Craik, Moreno \& Bialystok, 2013; Morales, Calvo, \& Bialystok 2013).

The general consensus is that bilingual language control - the experience of focusing on the intended language whilst avoiding intrusions from the unintended 
language - is the underlying cognitive process for the bilingual advantage in executive control (Green \& Abutalebi, 2013; Abutalebi \& Green, 2007). The underlying processes of bilingual language control are thought to include selecting which language to speak and inhibiting words from the language not intended for use. Additionally, those processes are believed to include the operation of monitoring potential conflicts between the language in use and the unintended one; for example, monitoring for interferences from the language not in use, as well as switching between languages (Green \& Abutalebi, 2013; Abutalebi \& Green, 2007).

However, the bilingual advantage has not been reliably observed. In terms of inhibitory control, a bilingual advantage was for instance not (consistently) reported in Gathercole et al. (2014), Kirk, Fiala, Scott-Brown, \& Kempe (2014), Mor, Yitzhaki-Amsalem, \& Prior (2014), Paap \& Sawi (2014), Paap \& Greenberg (2013), Namazi \& Thordardottir (2010) and Morton \& Harper (2007), and in fact Paap \& Sawi (2014) and Paap \& Greenberg (2013) reported a bilingual disadvantage in inhibitory control in young adults. In tasks tapping working memory no language group difference was observed (Ratiu \& Azuma, 2014; Bonifacci, Giombini, Bellocchi, \& Contento, 2011; Engel de Abreu, 2011; Namazi \& Thordardottir, 2010; Martin-Rhee \& Bialystok, 2008). This has led to scepticism over the bilingual advantage (e.g., De Bruin, Treccani, \& Della Sala, 2014; Klein, 2015; Morton, 2015; Paap, Hunter, \& Sawi, 2015). 
Amid the recent challenges in the "bilingual advantage" literature several studies have investigated whether the alleged advantage extends to trilingualism (see Schroeder \& Marian, 2016) with inconsistent evidence. Following on from the hypothesis that the exercise of actively speaking two languages makes bilinguals experts in inhibitory control and working memory it can be argued that the exercise of actively speaking more languages, such as three, means higher expertise; that is, more inhibitory control and working memory. Supporting this is evidence to suggest that among older adults, speaking three or more languages (compared to one) has a more protective effect against developing dementia. For instance, Chertkow et al. (2010) found no protective effect of bilingualism, apart from in an immigrant cohort, but found a significant protective effect of speaking three or more languages. Also, a lower risk of a mild cognitive impairment diagnosis has been observed in individuals who spoke more than two languages, compared to bilinguals (Perquin et al., 2013). However, this multilingualism protective effect is not always found in the dementia literature (Alladi et al., 2013). Further support comes from Kavé, Eyal, Shorek \& Cohen-Mansfield (2008), who observed better cognitive performance on the Mini Mental State Examination (MMSE), and the Short Orientation Memory Concentration Test (OMCT) in multilinguals compared to trilinguals, and trilinguals compared with bilinguals. As per the present study’s classification, Kavé et al. (2008) classified those who reported speaking four or more languages as multilinguals. 
General fluid intelligence has also been observed to be higher in older multilinguals, compared to bilinguals, after controlling for childhood intelligence (Bak, Nissan, Allerhand, \& Deary, 2014). This needs further testing in older adults, in terms of executive function, such as inhibition and working memory.

It could also be the case - as speculated by Schroeder and Marian (2016) - that although trilinguals have a larger vocabulary and thus more competing words to inhibit/ignore there may be a ceiling effect on the number of words becoming activated and subsequently requiring inhibition. Support for this comes from Poarch \& van Hell (2012) who examined inhibitory control in five- to eight-year-old monolingual, second language learners, bilinguals and trilinguals, using the Simon task and a flanker arrow type task, and Poarch and Bialystok (2015), who examined this in eight-to 11-year olds using the flanker task. Neither study observed any differences between bilinguals and trilinguals, but both bilingual and trilingual children showed enhanced inhibitory control compared to monolinguals. Further supporting evidence comes from Paap, Johnson \& Sawi (2014), who examined this in young adults by pooling data from Paap \& Greenberg (2013) and Paap \& Sawi (2014), whereby Paap \& Greenberg (2013) reported a bilingual disadvantage in inhibitory control only in the Simon task, and Paap \& Sawi (2014) in both inhibitory control and in global RT. After pooling data from both papers, Paap et al. (2014) reported no evidence of a bilingual advantage on twelve markers of executive 
function, obtained from the Simon task, Flanker task and the antisaccade task. They did, however, report a bilingual and trilingual disadvantage, compared to monolinguals, in inhibitory control (Simon effect), but the groups performed similarly in terms of global RT. The bilinguals and trilinguals did not differ on either measure, and all groups showed similar global RT. Although the evidence in children and young adults is contradictory in terms of the direction of the advantage, it suggests that in children and young adults, there is no added benefit of managing three languages, as opposed to two.

The existing limited evidence, looking at children and young adults, is contradictory. It would be informative to examine this further in adults and look at any age-related effects. Previous research comparing bilinguals and monolinguals and age-related effects suggests that a bilingual advantage, compared to monolingualism, increases with age and that language group differences are more likely to be seen in older adults than young adults (Bialystok et al., 2014; Schroeder \& Marian, 2012; Salvatierra \& Rosselli, 2010; Bialystok et al., 2004). Whether the same trend is observed in trilinguals is intriguing. The aforementioned studies (except for Schroeder \& Marian (2012), who only looked at older adults) assigned participants to predetermined age groups. Given that the trajectory of the ageing process on cognitive function is heterogeneous and complex (e.g., Hartshorne and Germine, 
2015; Salthouse, 2009), it would prove useful to examine age on a continuum, as this can provide a clearer picture of any age-related effects.

The present study investigated the effects of trilingualism, bilingualism and monolingualism on performance on a Simon task and an N-back task. As inhibitory control and working memory have been argued to share common underlying mechanisms (e.g., Miyake and Friedman, 2012), it seems logical to assess working memory too. It was aimed to carefully control the language groups using strict criteria; monolinguals were not functionally fluent (able to hold a conversation) in any other language except their first language; bilinguals only spoke two languages on a daily basis; and trilinguals spoke three languages on a daily basis.

As previous research into age-related effects of bilingualism on inhibitory control and working memory (e.g., Bialystok et al., 2014, 2004; Salvatierra \& Rosselli, 2010) indicates that the differences between monolinguals and bilinguals increase with age, to the advantage of bilinguals, it is important to examine this in trilinguals. Age was examined on a continuum (from young to older adults) rather than in predetermined age groups. 


\section{Method}

The data reported are drawn from two experiments. Experiment 1 compared trilinguals, bilinguals and monolinguals on the Simon task, and Experiment 2 compared the same language groups on a sequential-number version of the N-back task. All participants in both studies, who came from various cultural and language backgrounds, had normal or corrected to normal vision, and over $65 \mathrm{~s}$ did not have an existing diagnosis of cognitive impairments or difficulties. Bilinguals were included if they spoke two languages on a daily basis and trilinguals if they spoke three languages on a daily basis. Ethics approval was obtained from the Humanities, Social Sciences and Health Studies Research Ethics Panel, at the University of Bradford and all participants provided informed consent.

\section{Characteristics of participants}

For Experiment 1 a total of 132 (95 females and 37 males) monolinguals $(\mathrm{n}=$ 40), bilinguals $(n=58)$ and trilinguals $(n=34)$ were recruited. Overall, participants age ranged from 18 to 70 years $(\mathrm{M}=29.86$ years, $\mathrm{SD}=13.80$ years $)$. All monolinguals had English as their first language and were not functionally fluent in any other language. Most bilinguals had English as their second language and various 
languages as their first language. Four had English as their first language. Trilinguals had various languages as a first language, as a second language and as a third language.

For Experiment 2 the same participants took part, including 10 more participants (eight monolinguals and two bilinguals) with a total of 142 participants (102 females and 40 males), ranging in age from 18 to 79 years $(\mathrm{M}=32.96, \mathrm{SD}=$ 17.49), divided into three groups of monolinguals $(n=48)$, bilinguals $(n=60)$ and trilinguals $(\mathrm{n}=34)$. As in Experiment 1, all monolinguals had English as their first language and were functionally fluent only in English, the majority of bilinguals had English as their second language (four had English as their first language) and various languages as their first language, and trilinguals had various languages as a first, second and third language.

\section{Measures}

Background Questionnaire. For both experiments, participants completed a background questionnaire, which included demographic information, physical and mental activity and language use. Participants in each language group were also asked which languages they spoke and age of L2 acquisition. Furthermore, they provided selfrated proficiency in L1 and L2 on a 5 -point scale $(1=$ very poor to $5=$ very good $)$ and 
language use per day in percentages (L1, L2 and L3 (trilinguals)) which totalled $100 \%$.

Simon task (Experiment 1). In this task, participants viewed red or blue squares in the left or right visual field on a computer screen. They were instructed to fixate on a central cross (“+”) which was present at the beginning of each trial (duration 1000 milliseconds) after which it vanished, followed by a $250 \mathrm{~ms}$ blank interval. After this, a blue or a red square appeared for 250 milliseconds. Participants were instructed to press the left key (the X key) each time a red square appeared and the right key (the . key) when a blue square appeared. On congruent trials the red square was presented on the left and blue on the right, and on incongruent trials, the red square appeared on the right and blue on the left. There were 40 congruent trials and 40 incongruent trials ( 80 trials in total), which were presented randomly. There were eight practice trials. It should be noted that between group differences have been previously observed on the Simon task, including as few trials as 28 (Bialystok et al., 2004, Experiment 1). The dependent variables investigated here were (i) the Simon effect (the difference in response time between incongruent and congruent trials) and (ii) global reaction time (RT) on both congruent and incongruent trials.

$N$-back task (Experiment 2). Participants performed a computerised sequentialnumber version of the N-back task (Gevins and Cutillo, 1993), where digits from 1 to 
9 were presented randomly at the centre of the screen, one at a time. To our knowledge, this type of N-back task has not been used before in bilingual/trilingual research. A practice trial preceded each condition and in each of the conditions a total of 90 numbers was presented. Each condition was divided into three blocks of 30 numbers. A brief break was taken between blocks (circa one minute) and an approximately two to three minute break was taken between conditions. Stimulus duration was 500 milliseconds, with an inter-stimulus interval of 3000 milliseconds. For the 1-back condition, each number was compared with the previously presented number to determine whether it was the same number (match) or not (non-match). For the 2-back condition, each number was compared with the number presented two numbers back. Approximately $30 \%$ of the numbers were match numbers and $70 \%$ non-match in both conditions. Participants were instructed to press a green key for match stimuli and a red key for non-match stimuli with their dominant hand, and to keep their fingers placed on the keys throughout the experiment. The N-back task is thought to capture the core of working memory, by placing great demands on the key processes associated with working memory, namely on-line monitoring, and continually updating and manipulation of information. The reaction time and error rate differences between 0-back and 1-back, 1-back and 2-back trials and so on, are thought to reflect the cost of managing the increased demands on updating (Jonides et al., 1997; Owen et al., 2005). The dependent variables under investigation were the 
following RT measures: (i) 1-back match, (ii) 1-back non-match, (iii) 2-back match, (iv) 2-back non-match, (v) N-back effect match and (vi) N-back effect non-match. To clarify (v) and (vi) are calculated as 2-back minus 1-back and are thought to reflect increasing load on working memory.

\section{Results by Task}

Simon Task. Mean response latencies (RTs) and mean accuracy scores were calculated for each participant, and only scores for correct responses were used in the analysis. Outliers of more than two SDs from the mean were excluded from the analysis (less than 5\%). The data were submitted to a multivariate GLM, with Simon effect RT and global RT as dependent variables with language group (monolinguals, bilinguals, trilinguals) as a fixed factor and age as a covariate. Education was also entered in the model to control socioeconomic status (Emmorey, Luk, Pyers, \& Bialystok, 2009; Bialystok et al., 2008). To investigate any age effects, an interaction term of language group $\mathrm{x}$ age was also included in the model. Accuracy did not differ across groups [monolinguals $($ mean $=92.74 \%)$, bilinguals $($ mean $=90.80 \%)$, trilinguals (92.03\%)]. 
Main Effect of Language Group. The multivariate GLM analysis revealed no main effect of education on the Simon effect RT or global RT. However, there was a main effect of language group on the global RT, F $(2,125) .=3.73, \mathrm{p}<.05$, although pairwise comparisons failed to find significance between each individual language group. The main effect of language group on the Simon effect did not reach significance (N.S.), see Figure 1.

+++++ Figure 1 HERE +++++

The multivariate GLM also revealed a strong main effect of age on both the Simon effect $(\mathrm{F}(1,125) .=5.54, \mathrm{p}=.02)$ and global RT $(\mathrm{F}(1,125) .=15.64, \mathrm{p}<.001)$, where participants showed an increased magnitude of the Simon effect and were slower with age. This is an unsurprising result as a number of studies have shown that RTs on the Simon effect increase with age (Van der Lubbe \& Verleger, 2002; Bialystok et al., 2004; Salvatierra \& Rosselli, 2010).

Language group $x$ age interaction. As stated previously, language group $\mathrm{x}$ age interaction was submitted to the model and an interesting pattern emerged. The magnitude of the Simon effect seemed to be differentially affected by age, and 
language group. See Figure 2. The multivariate GLM analysis revealed this interaction (language $\mathrm{x}$ age) to be both significant for the Simon effect with F $(2,125)$. $=3.83, \mathrm{p}<.03$, and for the global RT, with $(\mathrm{F}(2,125) .=4.47, \mathrm{p}<.02)$. The parameter estimates revealed that for the Simon effect a significant linear relationship with age was seen only for the trilingual group. This indicates that the ability to inhibit irrelevant information remained stable with age in monolinguals and bilinguals but decreased in trilinguals. See Table 1 and Figure 2. Regarding the significant language $\mathrm{x}$ age interaction for the global RT, parameter estimates show a linear relationship with age for monolinguals and trilinguals whereby both groups show a significant increase in RTs with increasing age. No significant linear relationship was seen for bilinguals. See Table 1 and Figure 2.

+++++ Table 1 HERE +++++

+++++++ Figure 2 HERE +++++++ 
$N$-back Task. By definition, the first number of each block for the 1-back and first two numbers of each block for the 2-back were non-match so the responses to these stimuli were not included in the analysis. RTs longer than two standard deviations from the mean were removed for each participant (less than 5\%). RTs and accuracy scores (ACC) for successful matches and non-matches were only used in the analysis. The data were submitted to a multivariate general linear model (GLM), with match and non-match N-back effect RT, 1-back match and non-match RT and 2back match and non-match RT as dependent variables with language group (monolinguals, bilinguals, trilinguals) as a fixed factor and age and years of education as covariates. To examine any age effects, an interaction term of language group $\mathrm{x}$ age was also included in the model. The language group $\mathrm{x}$ age interaction was nonsignificant and was therefore taken out of the model.

There was a decline in accuracy with increased task difficulty across the language groups $[1$-back $($ mean $=92.75 \%)$, 2-back $($ mean $=89.09 \%), \mathrm{t}(141) .=$ $5.61, \mathrm{p}<.001]$, but accuracy did not significantly differ between the language groups, except one measure (N-back effect (non-match)), whereby trilinguals $\mathrm{N}$-back effect (non-match) was significantly larger $(\mathrm{p}<.04)$ than of bilinguals.

Main effect of language group. The Multivariate GLM RT analysis revealed a main effect of education on 1-back non-match, $(\mathrm{F}(1,137)=4.75, \mathrm{p}<.04)$, and a trend 
on 1-back match $(\mathrm{p}=.06)$ and a main effect of language group on 1-back match $(\mathrm{F}$ $(2,137)=4.05, \mathrm{p}<.02), 1$-back non-match $(\mathrm{F}(2,137) .=5.95, \mathrm{p}=.003), 2$-back match $(\mathrm{F}(2,137)=7.06, \mathrm{p}=.001), 2$-back non-match $(\mathrm{F}(2,137)=4.75, \mathrm{p}=.01)$, and marginally on N-back effect match, $(\mathrm{F}(2,137) .=2.96, \mathrm{p}=.055)$. Pairwise comparisons show that monolinguals responded significantly faster than trilinguals to 1-back match $(\mathrm{p}<.02)$, faster than bilinguals $(\mathrm{p}=.02)$ and trilinguals $(\mathrm{p}=.005)$ to 1 back non-match, marginally faster than bilinguals $(p=.076)$ and faster than trilinguals $(\mathrm{p}=.001)$ to 2 -back match, faster than bilinguals $(\mathrm{p}<.03)$ and trilinguals ( $\mathrm{p}<.03)$ to 2-back non-match and showed a smaller N-back effect (match) than trilinguals $(\mathrm{p}<.05)$. See Figures 3 and 4 . The only measure that did not reach significance regarding language group was the N-back effect non-match.

+++++++ Figure 3 HERE ++++++

++++++ Figure 4 HERE 


\section{Age effects}

The multivariate GLM analysis also revealed a main effect of age on all six measures $($ all $=\mathrm{p}<.001)$. Parameter estimates revealed a positive linear and highly significant relationship between age and all six measures. This confirms age as significant predictor of RT performance, with a stronger relationship with age as load increases. See Table 2. However, as stated above the interaction between language group and age was non-significant, indicating that age affected all groups similarly.

\footnotetext{
++++++ Table 2 HERE ++++++++
} 


\section{Discussion}

This study examined whether the bilingual advantage would extend to and become more enhanced in trilinguals compared to bilinguals. This was investigated using the Simon task, a well-known task in the bilingual advantage literature, and a complex numerical version of the N-back task. To our knowledge, this particular version of the N-back task had not been used before to compare working memory performance in bilinguals or trilinguals. A secondary aim was to explore how language group performance is affected by age, by looking at overall change across age rather than comparing predetermined age groups, a method often adopted in previous studies, such as Bialystok et al. $(2014,2004)$ and Salvatierra and Rosselli (2010).

The bilinguals and trilinguals recruited for this study had balanced proficiency in L1 and L2 but various languages as their first, second and third, and came from different cultural backgrounds, but all lived in Bradford. Thus, they are representative of many bilinguals and trilinguals in the world, and therefore it was important to address the hypothesised trilingual advantage in this population. Some had used more than one language all their lives, whilst others only for a short period of time. An advantage in inhibitory control has been reported in adult L2 language learners, compared to monolinguals (Linck, Hoshino, \& Kroll, 2008), so having a wide range 
of AoA was not predicted to be disadvantageous for the bilinguals and trilinguals recruited for this study. Unsurprisingly, residing in a country where English is the official language, bilinguals used their L2 (English) more than their L1 on a daily basis and trilinguals, which for most had English as their L3, used L3 the most on a daily basis, although this did not always reach significance.

In terms of inhibitory control, the data shows that there was no measurable difference between monolinguals, bilinguals and trilinguals on the Simon effect. Importantly this was not predicted by language acquisition or language use. However, the data suggest that the Simon effect was affected by age in trilinguals only. That is, whilst monolinguals and bilinguals' performance remained unchanged with increasing age there was an age-related decline in trilinguals. Importantly, this was not predicted by either language acquisition or language use. These results suggest that monolingualism and bilingualism, but not trilingualism, attenuate agerelated decline in inhibitory control. In terms of bilingualism, this is not in line with Bialystok et al. (2014, 2004), Salvatierra and Rosselli (2010) or Schroeder and Marian (2012), who found only bilingualism to attenuate age-related decline in inhibitory control, but not monolingualism. However, it is partly consistent with Paap et al. (2014), who found a trilingual disadvantage compared to monolinguals and bilinguals. 
The data here suggest that including trilinguals in a bilingual sample could have skewed data from previous studies. This is important considering that some studies have not controlled for trilinguals or multilinguals in their "bilingual" group as strictly as the present study (e.g., Coderre and van Heuven, 2014; Alladi et al., 2014; Paap and Sawi, 2014; Paap and Greenberg, 2013) and in the light of inconsistent findings in this field. Thus, the possible confounding effect of the presence of trilinguals or multilinguals in a "bilingual" cohort must be considered in future studies. The fact that some researchers report that their "bilingual" cohort included multilinguals suggests that this may be a problem in the literature. The data from the present study indicates that, at least in terms of inhibitory control, under some circumstances trilinguals and bilinguals' performance differs. This calls for more careful language group allocations, whereby bilinguals, trilinguals, quadringuals and so forth are separated.

In terms of working memory, the results clearly revealed a bilingual and trilingual disadvantage, compared to monolinguals. Although the data indicate a gradual decrease in performance with increasing number of languages, the difference between bilinguals and trilinguals did not yield significance. This was not predicted by language acquisition, and not by language use in trilinguals. However, language use predicted two of the non-match N-back measures (2-back and N-back effect), indicating worse performance with a more dominant use of one language. It is not 
clear why language use predicted only the aforementioned measures, and in bilinguals only, but this may indicate that only under complex conditions language use matters.

The working memory results suggest that managing two or three languages, compared to just one, can have a negative impact on working memory, as was seen with inhibitory control, contrasting with earlier findings of the advantageous effect of bilingualism on working memory (Bialystok et al., 2014). In children, a bilingual advantage was observed in two types of working memory tasks; a visuospatial task and a Simon task with added working memory manipulation (Morales et al., 2013). It is noteworthy, however, that some studies did not find any group differences (between monolingual and bilingual children) on various working memory tasks (Namazi \& Thordardottir, 2010; Engel de Abreu, 2011; Engel de Abreu et al., 2012). The bilingual and trilingual disadvantage reported here does, however, fit with recent evidence by Paap et al. (2014), who reported a bilingual and trilingual disadvantage, compared to monolinguals, in the Simon task (greater Simon effect).

Individuals with chronic tinnitus have been observed to have weaker inhibitory control compared to healthy controls (Heeren et al., 2014). The finding of Heeren et al. (2014) indicates that individuals with tinnitus do not develop enhanced inhibitory control, even after extensive practice of inhibiting/ignoring phantom sounds for around 11 years on average, suggesting attention overload on the cognitive 
system. Although the way bilingualism and tinnitus affect the cognitive system is not entirely comparable - and like bilingualism, tinnitus is a complex phenomenon (The British Tinnitus Association, 2015) - it can be argued that these phenomena are analogous up to a certain extent, as both groups are thought to experience extensive practice in inhibiting/ignoring irrelevant information. Thus, there is the possibility that managing two languages, compared to only one, presents attention overload, making it more challenging for bilinguals to complete executive function tasks. Similarly, it could be argued that as trilinguals have more languages to inhibit/ignore compared to bilinguals, they may experience an even heavier attention overload, and consequently find it even more challenging to complete executive function tasks than bilinguals. This could explain the present trilingual and bilingual disadvantage findings presented here, and those by Paap \& Greenberg (2013) and Paap \& Sawi (2014). Thus, there is the possibility that with increasing number of languages one speaks the heavier the attention overload. Hence, the more languages spoken, the more challenging it is to complete executive function tasks. This could partly explain the Simon effect finding presented here and those by Paap \& Greenberg (2013) and Paap \& Sawi (2014). However, our results also suggest that this might be manipulated by age as only trilinguals' performance on the Simon effect declined with age, whereas that of bilinguals' remained stable. Perhaps the attention overload 
only has its effect with the third language, and with age. Whether this is the case, and at what exact age is unclear and should be explored in future studies.

It could be argued that since the bilinguals and trilinguals in this study had various languages this could have influenced the results. This has indeed been conjectured (e.g., Hilchey and Klein, 2011). Support for this argument may come from studies by Paap and Greenberg (2013) and Paap and Sawi (2014), who recruited young bilinguals with various L1 languages, and either found no difference or a bilingual disadvantage in the Simon task, which may, in turn, be explained by various L1 languages. However, at least two studies which employed bilinguals from various cultural and language backgrounds found a bilingual advantage (Bialystok et al., 2014; Luo et al., 2013).

Future work should extend the investigation of trilingualism and inhibitory control/working memory to quadrilinguals, quintilinguals and so forth. Furthermore, other functions that have been associated with bilingual advantage, such as task switching, episodic memory and creativity are also important to address in trilinguals. 


\section{Conclusion}

By investigating age on a continuum rather than comparing predetermined age groups a complex relationship among the language groups was observed, whereby trilinguals showed a weakened inhibitory control performance with increasing age whereas all three language groups demonstrated similar effects of age in working memory performance. Moreover, these results were not confounded by L2 acquisition, but in terms of working memory some effects of language use were observed. Importantly, the results presented here raise questions about the prominence of the bilingual "advantage", how bilinguals are defined and allocated to groups, and suggests that trilingualism (and bilingualism) can in some cases have a negative impact on inhibitory control and working memory, when compared to monolingualism. Perhaps this finding is because of an overload of attention which requires inhibitory processing; further study is required. 


\section{Acknowledgements}

The authors would like to thank all the participants for taking part in the study.

Thanks also go to Dr. Giovanni Ottoboni for help with construction of the Simon paradigm and to Dr. Paul Morrill for help constructing the tests specifically for this study. 


\section{References}

Abutalebi, J., \& Green, D.W. (2007). Bilingual language production: The neurocognition of language representation and control. Journal of Neurolinguistics, 20(3), 242-275.

Alladi, S., Bak, T.H., Duggirala, V., Surampudi, B., Shailaja, M., Shukla, A.K., Chaudhuri, J.R., \& Kaul, S. (2013). Bilingualism delays age at onset of dementia, independent of education and immigrations status. Neurology, 81(2), 1938-1944.

Bak, T.H., Nissan, J.J., Allerhand, M.M., \& Deary, I.J. (2014). Does bilingualism influence cognitive aging? Annals of Neurology, 75(6), 959-963.

Bialystok, E., Craik, F.I.M., Klein, R., \& Viswanathan, M. (2004). Bilingualism, aging, and cognitive control: Evidence from the Simon task. Psychology and Aging, 19(2), 290-303.

Bialystok, E., Craik, F.I.M., \& Luk, G. (2008). Cognitive control and lexical access in younger and older adults. Journal of Experimental Psychology: Learning, Memory and Cognition, 34(4), 859-873. 
Bialystok, E., Craik, F.I.M., \& Ryan, J. (2006). Executive control in a modified antisaccade task: Effects of aging and bilingualism. Learning, Memory and Cognition, 32(6), 1341-54.

Bialystok, E., \& DePape, A.-M. (2009). Musical expertise, bilingualism, and executive functioning. Journal of Experimental Psychology. Human Perception and Performance, 35(2), 565-574.

Bialystok, E., Poarch, G., Luo, L., \& Craik, FIM. (2014). Effects of Bilingualism and Aging on Executive Function and Working Memory. Psychology and Aging, 29(3), 696-705.

Blumenfeld, H.K., \& Marian, V. (2014). Cognitive control in bilinguals: Advantages in Stimulus-Stimulus inhibition. Bilingualism: Language and Cognition, 17(3), 610629.

Blom, E., Küntay, A.C., Messer, M., Verhagen, J., \& Leseman, P. (2014). The benefits of being bilingual: working memory in bilingual Turkish-Dutch children. Journal of Experimental Child Psychology, 128, 105-119.

Bonifacci, P., Giombini, L., Bellocchi, S., \& Contento, S. (2011). Speed of processing, anticipation, inhibition, and working memory in bilinguals. Developmental Science, 2, 256-269. 
Chertkow, H., Whitehead, V., Phillips, N., Wolfson, C., Atherton, J., \& Bergman, H. (2010). Multilingualism (but not always bilingualism) delays the onset of Alzheimer disease: evidence from a bilingual community. Alzheimer Disease and Associated Disorders, 24(2), 118-125.

Coderre, E.L., \& van Heuven, W.J.B. (2014). Electrophysiological explorations of the bilingual advantage: Evidence from a Stroop task. PLOS ONE, 9:7, e103424.

Costa, A., Hernández, M., \& Sebastián-Gallés, N. (2008). Bilingualism aids conflict resolution: Evidence from the ANT task. Cognition, 106(1), 59-86.

De Bruin, A., Treccani, B., \& Della Sala, S. (2014). Cognitive advantage in bilingualism: an example of publication bias? Psychological Science, 26(1), 99-107.

Emmorey, K., Luk, G., Pyers, J.E., \& Bialystok, E. (2008). The source of enhanced cognitive control in bilinguals: Evidence from bimodal bilinguals. Psychological Science, 19(12), 1201-1206.

Engel de Abreu, P. (2011). Working memory in multilingual children: Is there a bilingual effect? Memory, 19(5), 529-537.

Engel de Abreu, P., Cruz-Santos, A., Tourinho, C.J., Martin, R., \& Bialystok, E. (2012). Bilingualism enriches the poor: Enhanced cognitive control in low-income minority children. Psychological Sciences, 23(11), 1364-1371. 
Gathercole, V.C.M., Thomas, E.M., Kennedy, I., Prys, C., Young, N. Vinas-Guasch, N., Roberts, E.J. Hughes, E.K., \& Jones, L. (2014). Does language dominance affect cognitive performance in bilinguals? Lifespan evidence from pre-schoolers through older adults on card sorting, Simon, and metalinguistic tasks. Frontiers in Psychology, 5,11.

Gevins, A.S., Bressler, S.L., Cutillo, B.A., Illes, J., Miller, J.C., Stern, J., \& Jex, H.R. (1990). Effects of prolonged mental work on functional brain topography. Electroencephalography and Clinical Neurophysiology, 76(4), 339-350.

Goral, M., Campanelli, L., \& Spiro, A. (2013). Language dominance and inhibition abilities in bilingual older adults. Bilingualism: Language and Cognition, 18(01), 7989.

Green, D.W., \& Abutalebi, J. (2013). Language control in bilinguals: the adaptive control hypothesis. Journal of Cognitive Psychology, 25(5), 515-530.

Hartshorne, J.K., \& Germine, L.T. (2015). When does cognitive functioning peak? The asynchronous rise and fall of different cognitive abilities across the life span. Psychological Science, 26(4), 1-11.

Heeren, A., Maurage, P., Perrot, H., De Volder, A., Renier, L., Araneda, R., Lacroix, E., Decat, M., Deggouj, N., \& Philippot, P. (2014). Tinnitus specifically alters the 
top-down executive control sub-component of attention: evidence from the attention network task. Behavioural Brain Research, 269, 147-154.

Hernández, M., Costa, A., Fuentes, L.J., Vivas, A., \& Sebastián-Gallés, N. (2010). The impact of bilingualism on the executive control and orienting networks of attention. Bilingualism: Language and Cognition, 13(3), 315-325.

Hilchey, M.D., \& Klein, R.M. (2011). Are there bilingual advantages on nonlinguistic interference tasks? Implications for plasticity of executive control processes. Psychonomic Bulletin and Review, 18(4), 625-658.

Jonides, J., Schumacher, E.H., Smith, E.E., Lauber, E.J., Awh, E., Minoshima, S., \& Koeppe, R.A. (1997). Verbal working memory load affects regional brain activation as measured by PET. Journal of Cognitive Neuroscience, 9(4), 462-475.

Kapa, L.L., \& Colombo, J. (2013). Attentional control in early and later bilingual children. Cognitive Development, 28(3), 233-246.

Kavé, G., Eyal, N., Shorek, A., \& Cohen-Mansfield, J. (2008). Multilingualism and cognitive state in the oldest old. Psychology and Aging, 23(1), 70-78.

Kirk, N.W., Fiala, L., Scott-Brown, K.C., \& Kempe, V. (2014). No evidence for reduced Simon cost in elderly bilinguals and bidialectals. Journal of Cognitive Psychology, 26(6), 640-648. 
Klein, R.M. (2015). On the belief that the cognitive exercise associated with the acquisition of a second language enhances extra-linguistic cognitive functions: Is “Type-I incompetence" at work here? Cortex, 73, 340-341.

Linck, J.A., Hoshino, N. and Kroll, J.F. (2008). Cross-language lexical processes and inhibitory control. Mental Lexicon, 3(3), 349-374.

Luk, G., de Sa, E., \& Bialystok, E. (2011). Is there a relation between onset age of bilingualism and enhancement of cognitive control? Bilingualism: Language and Cognition, 14(4), 588-595.

Luo, L., Craik, F.I.M, Moreno, S., \& Bialystok, E. (2013). Bilingualism interacts with domain in a working memory task: evidence from aging. Psychology and Aging, 28(1), 28-34.

Martin-Rhee, M.M., \& Bialystok, E. (2008). The development of two types of inhibitory control in monolingual and bilingual children. Bilingualism: Language and Cognition, 11(01), 81-93.

Miyake, A., \& Friedman, N.P. (2012). The nature and organization of individual differences in executive functions. Current Directions in Psychological Science, 21(1), 8-14. 
Mor, B., Yitzhaki-Amsalem, S., \& Prior, A. (2014). The joint effect of bilingualism and ADHD on executive functions. Journal of Attention Disorders, 19(6), 1-15.

Morales, J., Calvo, A., \& Bialystok, E. (2013). Working memory development in monolingual and bilingual children. Journal of Experimental Child Psychology, 114(2), 187-202.

Morton, J.B. (2015). Still waiting for real answers. Cortex, 73, 352-353.

Morton, J.B., \& Harper, S.N. (2007). What did Simon say? Revisiting the bilingual advantage. Developmental Science, 10(6), 719-726.

Namazi, M., \& Thordardottir, E. (2010). A working memory, not bilingual advantage, in controlled attention. International Journal of Bilingual Education and Bilingualism, 13(5), 597-616.

Owen, A.M., McMillan, K.M., Laird, A.R., \& Bullmore, E. (2005). N-Back working memory paradigm: A meta-analysis of normative functional neuroimaging studies. Human Brain Mapping, 25(1), 46-59.

Paap, K.R., \& Greenberg, Z.I. (2013). There is no coherent evidence for a bilingual advantage in executive processing. Cognitive Psychology, 66(2), 232-258. 
Paap, K.R., Hunter, A.J., \& Sawi, O. (2015). Bilingual advantages in executive functioning either do not exist or are restricted to very specific and undetermined circumstances. Cortex, 69, 265-278.

Paap, K.R., Johnson, H.A., \& Sawi, O. (2014). Are bilingual advantages dependent upon specific tasks or specific bilingual experiences? Journal of Cognitive Psychology, 26(6), 615-639.

Pelham, S.D., \& Abrams, L. (2014). Cognitive advantages and disadvantages in early and late bilinguals. Journal of Experimental Psychology: Learning, Memory, and Cognition, 40(2), 313-325.

Perquin, M., Vaillant, M., Schuller, A., Pastore, J., Dartigues, J., Lair, M., Diederich, N., \& MemoVie Group. (2013). Lifelong exposure to multilingualism: new evidence to support cognitive reserve hypothesis. PLoS One, 8(4), e62030.

Poarch, G.J., \& Bialystok, E. (2015). Bilingualism as a model for multitasking. Developmental Review, 35, 113-124.

Poarch, G.J., \& van Hell, J.G. (2012). Executive functions and inhibitory control in multilingual children: Evidence from second-language learners, bilinguals, and trilinguals. Journal of Experimental Child Psychology, 113(4), 535-551. 
Ratiu, I., \& Azuma, T. (2014). Working memory capacity: Is there a bilingual advantage? Journal of Cognitive Psychology, 27(1), 1-11.

Salthouse, T.A. (2009). When does age-related cognitive decline begin? Neurobiology of Aging, 30, 507-514.

Salvatierra J.L., \& Rosselli M. (2010). The effect of bilingualism and age on inhibitory control. International Journal of Bilingualism, 15(1), 26-37.

Schroeder, S.R., \& Marian, V. (2016). Cognitive consequences of trilingualism. International Journal of Bilingualism, 21(6), 754-773.

Schroeder, S.R., \& Marian, V. (2012). A bilingual advantage for episodic memory in older adults. Journal of Cognitive Psychology, 24(5), 591-601.

Soveri, A., Rodriguez-Fornells, A., \& Laine, M. (2011). Is there a relationship between language switching and executive functions in bilingualism? Introducing a within group analysis approach. Frontiers in Psychology, 2, 1-8.

Tao, L., Marzecová, A., Taft, M., Asanowicz, D., \& Wodniecka, Z. (2011). The efficiency of attentional networks in early and late bilinguals: The role of age of acquisition. Frontiers in Psychology, 2, 123. 
The British Tinnitus Association (2015). All about tinnitus [online] <http://www.tinnitus.org.uk/documents/34> [Accessed 27 $7^{\text {th }}$ November 2015]

Van der Lubbe, R.H.J., \& Verleger, R. (2002). Aging and the Simon task. Psychophysiology, 39(1), 100-110.

Yang, S., Yang, H., \& Lust, B. (2011). Early childhood bilingualism leads to advances in executive attention: Dissociating culture and language. Bilingualism: Language and Cognition, 14(3), 412-422.

Yow, W.Q., \& Li, X. (2015). Balanced bilingualism and early age of second language acquisition as the underlying mechanisms of a bilingual executive control advantage: Why variations in bilingual experiences matter. Frontiers in Psychology, 6, 164. 


\section{Figure legends}

Figure 1. Mean reaction times (adjusted means) and standard errors for global RT and Simon effect measures by language group.

Figure 2. Scatter plots of the interaction between language group $x$ age for (a) the Simon effect and (b) the global RT.

Figure 3. Mean reaction times (adjusted means) and standard errors for 1-back and 2back measures (match and non-match) by language group.

Figure 4. Mean reaction times (adjusted means) and standard errors for the N-back effects (match and non-match) by language group. 
Table 1. Summary of the parameter estimates from the multivariate GLM for the language $\mathrm{x}$ age interactions. Significance stars demonstrate linear relationships between age and language group.

\begin{tabular}{|c|c|c|c|c|c|c|}
\hline & \multicolumn{2}{|c|}{ Age x Monolinguals } & \multicolumn{2}{|c|}{ Age $x$ Bilinguals } & \multicolumn{2}{|c|}{ Age $x$ Trilinguals } \\
\hline & $\mathrm{SE}$ & Global & $\mathrm{SE}$ & Global & $\mathrm{SE}$ & Global \\
\hline & & RT & & RT & & RT \\
\hline B & -.32 & 3.61 & .63 & .19 & 1.35 & 2.60 \\
\hline Standard & .33 & .76 & .36 & .84 & .52 & 1.19 \\
\hline Error & & & & & & \\
\hline$t$ & -.96 & $4.73 * *$ & 1.72 & .23 & $2.61 *$ & $2.19^{*}$ \\
\hline
\end{tabular}


Table 2. Summary of the parameter estimates from the multivariate GLM for the effects of age on the n-back RT measures. Significance stars demonstrate linear relationships between age and score.

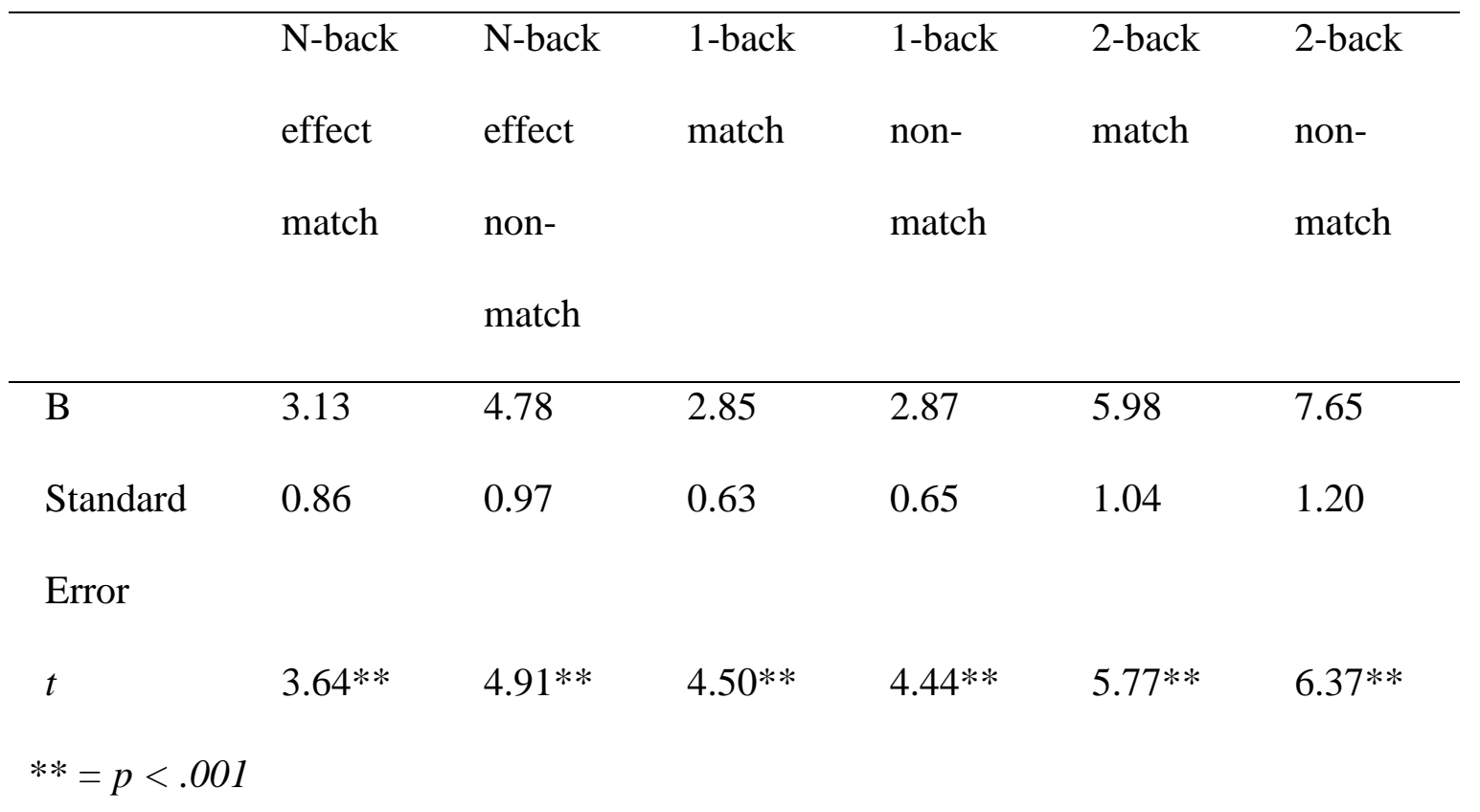

